\title{
What does the headless cockroach remember?
}

\author{
PAUL WILLNER \\ University of Oxford, Oxford, England
}

\begin{abstract}
Headless cockroaches were trained either to lift or to lower a leg to avoid electric shock. The difficulty of the lifting task depended on the position of the leg with respect to the criterion height. Savings on retraining were seen in the lifting task. However, following training, the leg was returned slowly to its original position, and differences in the position of the leg at the start of retraining were sufficient to account for the savings. No savings were seen in retraining in the lowering task. In addition, $15 \mathrm{~min}$ after training. no impairments were found in reversal training. However, reversal learning was impaired immediately following training. It is concluded that the preparation does not remember the correct avoidance response for as long as $15 \mathrm{~min}$. Hence, the preparation is unlikely to prove of value in elucidating the physiological bases of memory. Yoked controls were impaired in learning either the lifting or the lowering task. Impairment in the lifting task was found to persist for up to $1 \mathrm{~h}$ following a brief training period; this may represent a genuine memory phenomenon.
\end{abstract}

Many workers, in pursuit of the physiological bases of learning and memory, have chosen to shun the complexities of the mammalian central nervous system and concentrate on simplified preparations, in which learning or related phenomena are subserved by minimal quantities of nervous tissue, which, it is hoped, will prove more amenable to physiological analysis (Kandel \& Spencer, 1968). Invertebrate preparations are frequently chosen, owing to the ease of isolating parts of the nervous system. Two preparations which have received particular attention are the abdominal ganglion of the mollusc Aplysia (Kandel, 1974) and the ventral nerve cord of the cockroach (Horridge, 1962; Hoyle, 1965). Anatomical and physiological differences between vertebrate and invertebrate neurons (Cohen, 1970; Vowles, 1966) and recent concern with speciesspecific learning mechanisms (Bolles, 1971; Seligman \& Hager, 1972) highlight the possibility that the neural substrates of learning may be different for different species. In order to evaluate the relevance of studies on simplified invertebrate systems, it is necessary first to know the extent to which the behavioral processes studied resemble learning and memory in mammalian species.

The headless cockroach preparation is usually studied by comparing the performance of cockroaches trained to lift a leg to avoid shock with that of yoked controls, which receive the same electric shocks without the opportunity to escape or avoid

This research forms part of a thesis submitted to the University of Oxford for the degree of D.Phil. The author is grateful to the Science Research Council of Great Britain and The Queen's College, Oxford for financial support, to Dr. Jane Mellanby for her help and encouragement, and to Dr. F.H.C. Marriott for statistical advice. Present address: Psychology Department, City of London Polytechnic, Old Castle Street, London E.1., England. them. Church (1964) has argued that differences in performance between trained animals and yoked controls could be produced by random differences in responsiveness to shock, without involving learning. Briefly, such effects arise from the following asymmetry: if the trained animal makes an avoidance response, shocks to the yoked control cease, but if the control makes a response, the trained animal continues to receive shock. The argument has recently been applied specifically to the headless cockroach preparation (Church \& Lerner, 1976). In the light of this criticism, it is questionable whether learning does, in fact, occur. This critique is extended in the present paper. A series of experiments are presented which cast serious doubt upon the assumption that the headless cockroach can remember.

\section{EXPERIMENT 1}

In this paper, the word "learning" will be used for convenience, without prejudice to the argument that learning did not in fact occur (Church \& Lerner, 1976). In Parts A and B of the present experiment, the leg-raising learning situation first described by Horridge (1962) was examined, and it was shown that the exact placement of the leg with respect to the criterion height was important in determining the speed of learning. This is hardly surprising; however, in Part $\mathrm{C}$, it is shown that this factor gives rise to an artifact in testing retention, producing the unwarranted conclusion that the preparation remembered the correct response.

\section{Method}

Subjects. Adult male cockroaches (Periplaneta americana) were used in all experiments. They were taken from the colony maintained by the Oxford University Department of Zoology, and 
housed for not more than 2 days in plastic trays containing shredded tissue paper, food and water. Forty-eight animals were used in each of Parts A and B, and 240 in Part C. The subjects were always tested in pairs (one experimental animal and a yoked control).

Procedure. Each animal was first immobilized by cooling. It was then decapitated and five legs were removed at the trochanter, leaving only the left metathoracic leg intact. The animal was mounted by the dorsal surface to a glass microscope slide by means of beeswax. The neck was sealed with beeswax to minimize loss of haemolymph. One electrode $(0.1 \mathrm{~mm}$ silver wire) was inserted through a small hole pierced through the cuticle in the center of the tibia, and sealed in position with a dab of wax. A second electrode was connected to the neck of the animal. The tibial lead was coiled to minimize torque on the leg, and both leads were connected to terminals on top of the glass slide.

Three hours after operation, the animal was suspended in such a position that the leg could make contact with saline in a dish placed below it. Contact was detected by means of a curcuit through the tibial lead, the leg, and a third electrode in the saline. When the leg was in the saline, a current of less than $5 \times 10^{-7}$ A flowed in the detection circuit (the threshold for producing an observable response was roughly $5 \times 10^{-5} \mathrm{~A}$ ). The signal was amplified to trigger a solid-state modular logic system (Behavior Research and Development Ltd, Walton on Thames, Surrey, England), which was used to record the behavior of the preparation, and apply shocks when appropriate, via Grass SD5 stimulators (Grass Medical Instrumentation, Quincey, Mass, USA).

In Part A ("easy" task), the height of each animal was adjusted such that the leg just made contact with the saline. The mean height of the animals $( \pm \mathrm{SEM})$, measured from the saline surface to the glass slide, was found to be $1.93 \pm .03 \mathrm{~cm}$ for both experimentals and controls. The position of the leg was monitored for $15 \mathrm{~min}$ in the absence of shock. A 30-min training session then followed. During this time, one animal in each pair (the experimental, or trained, animal) was shocked (1 shock/sec at $0.4 \mathrm{~mA}$ and $0.2 \mathrm{msec}$ duration) whenever the leg made contact with the saline. Whenever the trained animal was shocked, a shock was also delivered to the second member of the pair (the yoked control). At the end of the training session, the animals which previously had been yoked were shocked when their legs made contact with the saline; their situation was thus identical with that of the trained animals during the training session. This test session lasted $15 \mathrm{~min}$.

The identical design was used for Part B ("difficult" task). The height of each animal was again adjusted so that the leg was just touching the saline; the mean heights ( \pm SEM) of the two groups were $1.91 \pm .02$ and $1.90 \pm .02 \mathrm{~cm}$, which did not differ significantly from those previously obtained. However, immediately prior to training, the saline bath was raised $3 \mathrm{~mm}$ for all animals. Thus, in the "difficult" task, the leg had to be raised an extra $3 \mathrm{~mm}$ in order to aviod shock.

In Part C, the 240 subjects were divided into 10 groups of 24. Mean heights above the saline were between 1.88 and $1.91 \mathrm{~cm}$; there were no significant differences between groups. Subjects in five of the groups were trained as in Part A ("easy" task); subjects in the other five groups were yoked controls. At the end of $6 \mathrm{~min}$ training, the stimulators were turned off, and the behavior of the animals was recorded during an extinction period. For the five groups, extinction lasted $0,12,30,60$, and $180 \mathrm{~min}$, respectively. At the end of this time, all 240 animals were trained for $6 \mathrm{~min}$ to avoid the saline

\section{Results}

Parts $A$ and $B$. At the start of training, all groups showed a large decrease in diptime (time of contact of the leg with the saline solution). Thereafter, during training, diptime in the experimental groups, but not in the controls, continued to decrease (Figure 1). The performance of trained animals was better in Part A (easy task) than in Part B (difficult task). Over the first $15 \mathrm{~min}$ of training, the mean diptime of trained animals was $7.3 \mathrm{sec} / \mathrm{min}$ in Part $A$ and $25.2 \mathrm{sec} / \mathrm{min}$ in Part $\mathrm{B}[\mathrm{t}(46)=6.2$, $\mathrm{p}<.001]$; the mean difference between trained animals and controls was $35.1 \mathrm{sec} / \mathrm{min}[\mathrm{t}(23)=$ $12.9, \mathrm{p}<.001]$ in Part $\mathrm{A}$ and $12.1 \mathrm{sec} / \mathrm{min}[\mathrm{t}(23)=$ $2.7, \mathrm{p}<.01]$ in Part $\mathrm{B}[\mathrm{A}-\mathrm{B}$ difference; $\mathrm{t}(46)=$ $5.1, \mathrm{p}<.001]$.

For each 15 -min period of training, the ratio of (total time dipped)/(number of dips) was calculated, to give an estimate of length of dips. In the difficult task, there was a significant fall in mean diplength of trained animals, from 15.5 to $4.7 \mathrm{sec}$ $[\mathrm{t}(23)=2.1, \mathrm{p}<.05]$; in the easy task, there was an insignificant decrease from $3.6 \mathrm{sec}$ to $2.0 \mathrm{sec}$ [ $\mathrm{t}(23)$ $=1.4, \mathrm{p}>0.1]$.

The performance of previously yoked controls on test (Figure 1) was substantially impaired in both tasks, relative to the performance of experimental animals in their first 15 min of training [ $t(23)=$ 3.7, 5.5; $\mathrm{p}<.001$ ]. Controls in Part $\mathrm{A}$ did show an inprovement over their performance in the previous $15 \min [\mathrm{t}(23)=6.2, \mathrm{p}<.001]$, but controls in Part $B$ did not $[\mathrm{t}(23)=0.5, \mathrm{p}>.1]$.

Part C. The five groups of trained animals and yoked controls were well matched in initial training. Analysis of variance (Groups by Conditions) performed on the total diptime over the 6 min showed no differences among the five groups $[F(4,92)=$ 1.1] but a significant difference between trained

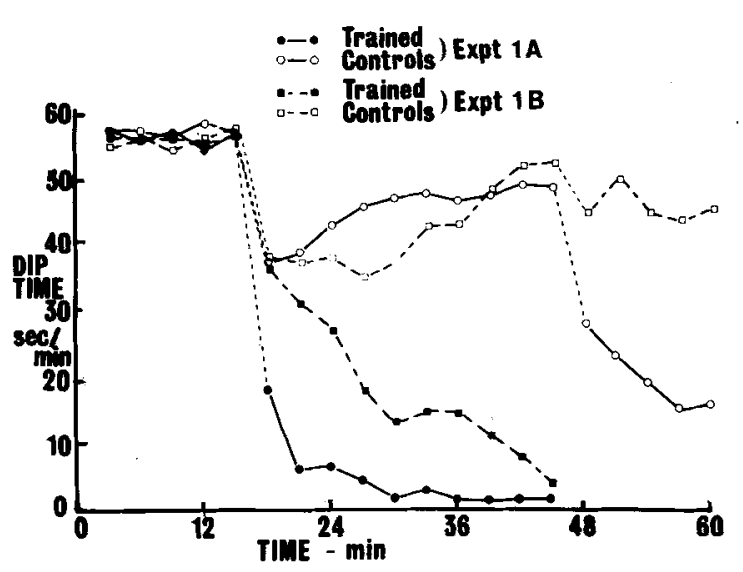

Figure 1. Diptime during training in the leg-lifting task. During Minutes $0-15$, no treatment was applied; experimentals and controls both received shocks whenever the leg of the experimental animal was in contact with the saline during Minutes 15-45; and during Minutes 45-60, controls received shocks whenever the leg was in contact with the saline. 
animals and controls $[F(1,23)=208, p<.001]$. A second analysis of variance performed on the total number of dips made during training, again showed no significant differences among groups $[F(4,92)=$ $0.9]$ and also no difference between trained animals and controls $[F(1,23)=1.9]$.

At short intervals between training and testıng, performance of trained animals was much better during testing than in original training, but with an increase in the length of the intervening extinction period, the number of shocks taken during testing increased (Figure 2). The reverse was true for previously yoked animals; initially, they received more shocks than naive animals, but the number of shocks taken decreased as the training-testing interval increased. Trained animals received significantly fewer shocks than in their original training when tested immediately, or at 12 or $30 \mathrm{~min}$ $[\mathrm{t}(23)=4.3,5.2,4.2 ; \mathrm{p}<.001]$ but were not significantly better at $60 \mathrm{~min}$ or $3 \mathrm{~h}(\mathrm{t}(23)=1.3$, $1.3 ; \mathrm{p}>.05]$. Yoked animals received significantly more shocks than the naive animals with which they had been paired, when tested immediately $[\mathrm{t}(23)=$ $3.0, \mathrm{p}<.01]$ or after $12 \mathrm{~min}[\mathrm{t}(23)=5.1, \mathrm{p}<.001]$, $30 \mathrm{~min}[\mathrm{t}(23)=2.6, \mathrm{p}<.01]$, or $60 \mathrm{~min}[\mathrm{t}(23)=$ $1.8, \mathrm{p}<.05]$; they were not significantly impaired after $3 \mathrm{~h}[\mathrm{t}(23)=0.7, \mathrm{p}>.05]$. At $3 \mathrm{~h}$, the number of shocks received in testing by previously trained and previously yoked animals did not differ significantly $[\mathrm{t}(23)=1.4, \mathrm{p}>.05 \mathrm{j}$.

Diptime during extinction is shown in Figure 3. Both trained animals and controls dipped more as extinction progressed. However, the difference between them was maintained at a significant level

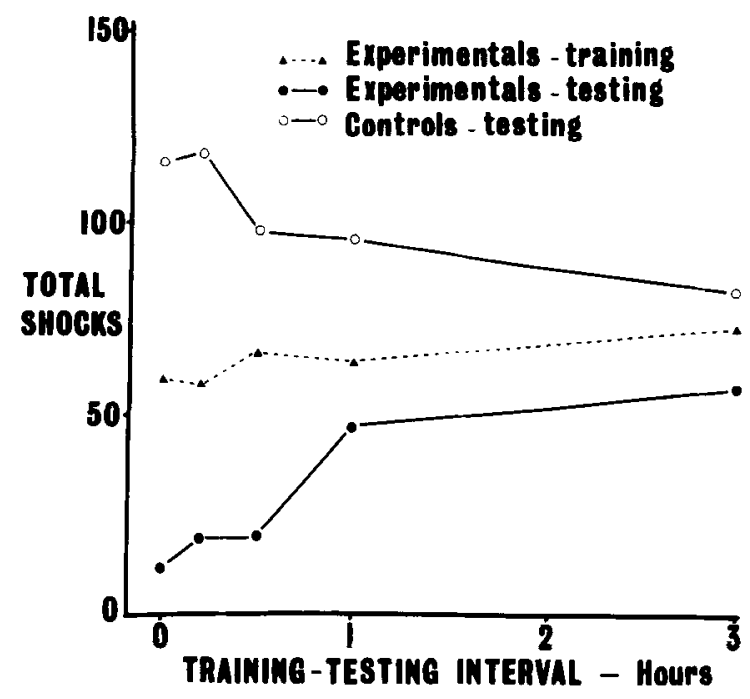

Figure 2. Total shocks received by experimental animals during training, and by experimentals and controls during testing, at varying training-testing intervals.

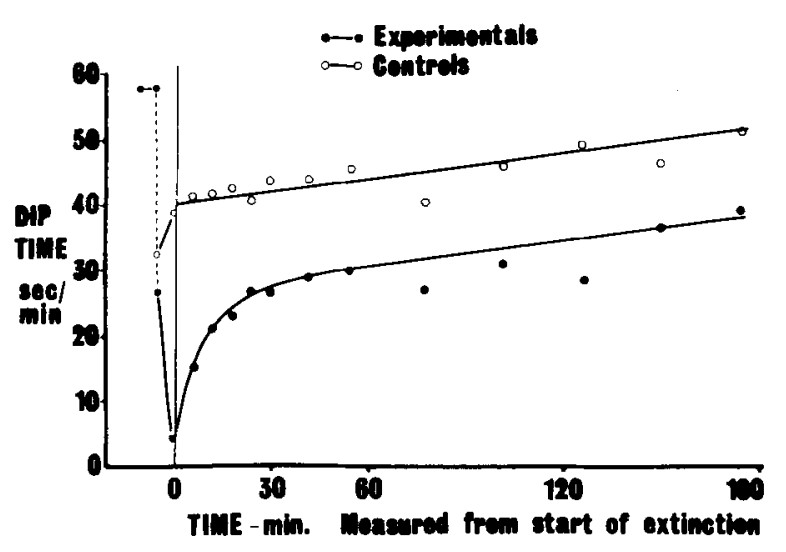

Figure 3. Extinction of a lifting response. Following training on the easy lifting task (12 min before training and first and last minutes of training shown to left of time 0 ), trained animals and yoked controls were left in situ without shock, and their diptime was measured during extinction.

throughout the $3 \mathrm{~h}(\mathrm{p}<.05, \mathrm{t}$ tests). Moreover, at all times controls had a significantly lower diptime than in the period prior to training $(p<.01, t$ tests, with the exception of the final point, for which $\mathrm{t}=2.3, \mathrm{p}<.05$ ).

A significant correlation was found between the number of shocks received by trained animals during retraining, and their diptime recorded during the last $6 \mathrm{~min}$ of extinction $[\mathrm{r}(95)=0.31, \mathrm{p}<.01]$. (Individual values were first standardized about their group mean, in order to eliminate differences between groups.) Thus, within-group variations in retraining scores depended on variations in diptime at the start of retraining. An analysis of covariance was carried out to examine the extent to which between-group differences in retraining scores might also be related to extinction performance (Sprott, 1970). Retraining scores (R) were examined at different retraining intervals (RTRI), taking diptime at the end of extinction $(E)$ as a covariate. The original analysis of variance was highly significant $[F(3,42)=4.6, \quad p<.01]$; however, the residual (within-groups) regression of $R$ on $E$ was also significant $[F(1,91)=6.9, p<.01]$. When $R$ scores were adjusted to take account of this regression, the analysis of variance ( $R$ vs. $R T R I)$ no longer gave a significant result $[F(3,91)=2.5, \mathrm{p}>.05]$. This means that the differences in the retraining scores shown by the four groups could be accounted for in terms of differences in diptime obtaining immediately proir to retraining, i.e., the extent to which the response was extinguished. There was no significant effect of retraining interval per se.

\section{Discussion}

The results of Parts A and B show clearly that the speed of learning of the leg-lifting response is 
dependent on task difficulty, as defined by the height above the saline at which the leg is held at the start of training. Similar results have been observed in other experiments, for example, Experiments $1 \mathrm{C}$ and $3 \mathrm{~A}$ of the present paper (easy task) and Willner and Mellanby (1974), Figure 3 (difficult task). Differences in height could account for certain discrepancies in the literature. For example, time to achieve asymptotic performance has been reported at anything between $1.5 \mathrm{~min}$ (Disterhoft, 1972) and $1 \mathrm{~h}$ (Horridge, 1962). Similarly, Eisenstein (1967), Kerkut et al. (1970), and Rick et al. (1972) reported that headless animals learn better than intact animals, but Horridge (1965) found no such difference. This discrepancy might be expected if headless animals tended to hold the leg lower than intact animals, which would say nothing about relative learning abilities. Clearly, the leg position must be carefully controlled. However, it has not been reported in any previous study.

The importance of this factor becomes clear in considering the results of Part $C$. Performance on retraining, within a group of animals tested at the same interval, was significantly correlated with the starting position of the leg; further analysis showed that there was no significant effect of time elapsed since training over and above the effect on leg position at the start of testing. Animals tested earlier received fewer shocks because they were given an easier task to learn, not because they remembered the correct response. Pritchatt (1970) found changes in leg position were sustained after 20 min training but not after $6 \mathrm{~min}$; similarly, using the procedure of the present experiment, Willner (1974) found sustained changes in leg position after 6 min training but not after $3 \mathrm{~min}$. While these effects may be interesting in themselves, they are not what is usually meant by "memory." Sustained changes in leg position were also seen in the yoked controls. This point receives further discussion below.

Three further points arise from the present experiments. First, the finding of no difference in rate of dipping between experimentals and controls is at variance with Eisenstein's claim that experimentals were more active. Eisenstein found that experimentals made roughly $7 \mathrm{dips} / \mathrm{min}$ during the first 5 min of training, and controls, 3; it was not, however, reported that the result was statistically significant (Eisenstein, 1970a). Second, it is clear that the change in behavior shown by trained animals involved a decrease in the length of dips. This was only seen in the difficult task, probably owing to a "floor effect" in the easy task. Disterhoft (1972) considered such a change to be evidence of escape learning, and failed to observe it, but this may be because a particularly easy task was used (asymptotic performance in $1.5 \mathrm{~min}$ ). Third, the yoked control impairment presents a problem of interpretation, which will be discussed below.

\section{EXPERIMENT 2}

The present experiment employed a technique different from that of Experiment 1, namely, the training of a leg-lowering avoidance response. This has previously been reported by Pritchatt (1968, 1970), using intact cockroaches (Periplaneta americana). In the 1968 paper, a convincing difference was produced between trained animals and yoked controls. However, only the difference scores were reported, so it is unclear how good the learning was in terms of the number of shocks received. But in the 1970 paper, it appeared that the training had very limited results; over a 20 -min training period, the mean time dipped was only $13 \mathrm{sec} / \mathrm{min}$ (calculated from Pritchatt, 1970, Figure 4), and from the earlier paper (Pritchatt, 1968, Figure 6), it would seem that the improvement with time is slight. Thus, the only experiments reported in the literature in which cockroaches were trained to lower the leg to avoid electric shock, obtained a poor performance. To date, there has been no report of even this measure of success in the headless preparation.

The reason for the difficulty became clear in preliminary experiments. Headless cockroaches were suspended such that the leg was just above the surface of a saline bath, and shocks were applied whenever the leg failed to make contact with the saline. However, the unconditioned response to shock was to raise the leg (see Experiment 1), which meant that as soon as training began, the task became more difficult. It was not feasible to make the task easier, since lowering the animal brought the leg into contact with the saline. The procedure adopted to circumvent this dilemma was first to position the animal at the start of the experiment with the leg in the saline, then to present a small number of shocks to stimulate leg withdrawal, and only then to make shock contingent on lack of contact with the saline. Parts A and B describe the success of this technique, using two different shock durations.

The results of Experiment 1 suggested that the apparent savings on retraining on the leg lowering task were an artifact of the very slow time course over which the leg was returned to the resting position. The leg displacement artifact does not apply in the situation employed in the present experiment; it could therefore be predicted that no savings would be seen on retraining on the lowering task. This hypothesis was tested in Part C.

\section{Method}

Twenty-four pairs of cockroaches were used in Part A, 32 pairs in Part B, and a single group of 24 in Part C. The 
animals were prepared for the experiment as for Experiment 1. Prior to training, the animals were suspended such that the leg just made contact with a dish of saline, and the position of the leg was monitered for $6 \mathrm{~min}$, in the absence of shock. Heights above the saline recorded during this period were not significantly different from those observed in Experiment 1.

In Parts A and B, all animals then received 30 shocks of $.4 \mathrm{~mA}$ and $.2 \mathrm{msec}$ duration, applied as trains of 10 shocks at 1 -sec intervals, delivered at the beginning of each of 3 successive minutes. In Part A, a 30-min training period followed, during which one animal in each pair was shocked $(.4 \mathrm{~mA}, .2 \mathrm{msec}$, $1 / \mathrm{sec})$ whenever the leg failed to make contact with the saline. The second member of the pair was yoked to receive shocks at the same time as the first. After $\mathbf{3 0}$ min of training, the yoke was broken, and the previously yoked animal was trained for $30 \mathrm{~min}$ on the schedule described above. The identical procedure was followed for Part B, except that the shock duration was increased to $2.0 \mathrm{msec}$, and the experiment terminated after $15 \mathrm{~min}$ of training.

In Part $C$, all animals received 10 shocks $(.4 \mathrm{~mA}, .2 \mathrm{msec}$, $1 / \mathrm{sec}$ ) and training began $20 \mathrm{sec}$ later; during the 15 -min training period, the animals received shocks $(.4 \mathrm{~mA}, 2.0 \mathrm{msec}, 1 / \mathrm{sec})$ whenever the leg failed to contact the saline. At the end of this period, no shocks were delivered for $15 \mathrm{~min}$; the sequence of 10 shocks followed $20 \mathrm{sec}$ later by a 15 -min training period was then repeated.

\section{Results}

Part A. The preparation readily learned to perform the leg-lowering response. It may be seen (Figure 4) that the 30 shocks applied before training produced a fall in diptime in both groups (i.e., the leg was raised above the saline). During training, there was a gradual increase in the diptime of the trained group, and a clear difference appeared between trained animals and yoked controls; the mean difference over the first $15 \mathrm{~min}$ of training was $19.1 \mathrm{sec} / \mathrm{min}[\mathrm{t}(23)=4.4, \mathrm{p}<.001]$. When yoked controls were tested with contingent shock in the final part of the experiment, they showed a sub-

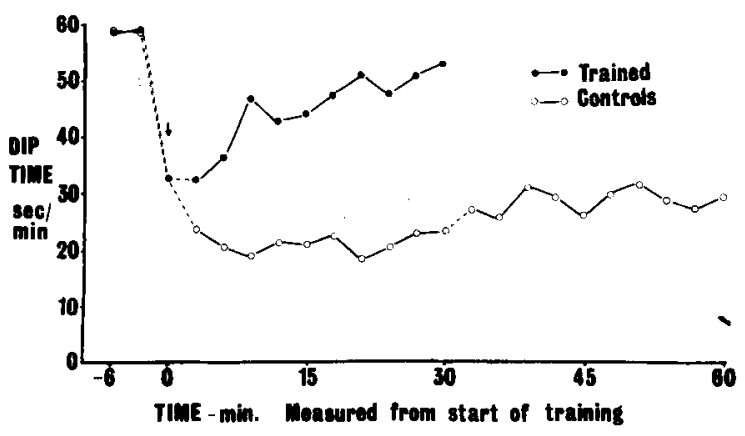

Figure 4. Diptime during training on the lowering task. Headless cockroaches were suspended for 6 min above dishes of saline, such that the leg just made contact with the saline, then given 30 shocks to induce leg lifting (marked with arrow). During Minutes 0-30, experimentals and controls both received shocks whenever the leg of the experimental animal was not in contact with the saline; during Minutes 30-60, controls received shocks whenever the leg was not in contact with the saline.

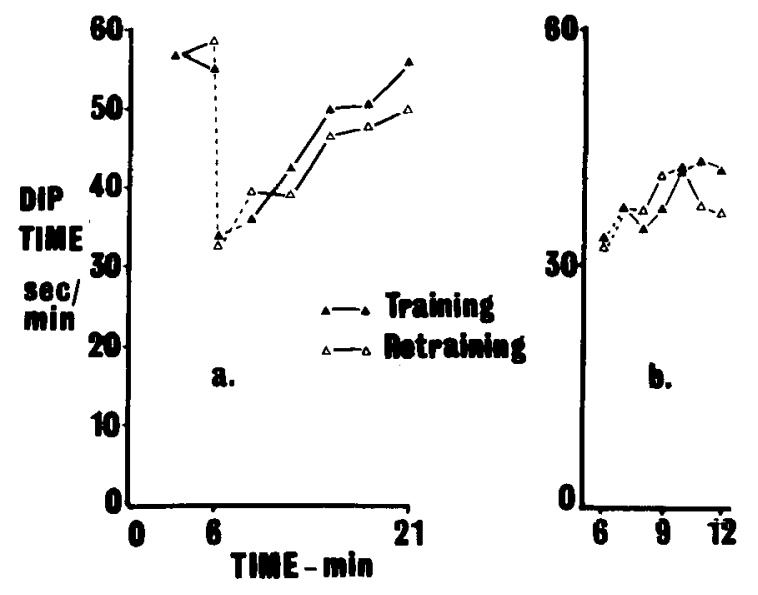

Figure 5. Retention of a leg-lowering response. Headless cockroaches were suspended with the leg in contact with saline for $6 \mathrm{~min}$, then given 10 shocks to induce leg lifting, and trained for $15 \mathrm{~min}$ to lower the leg; this was repeated after a 15-min delay. (a) Graphs of diptime during the period (6 min before training - end of training) and (6 min before retraining-end of retraining) are superimposed. (b) Graphs of diptime during the first 6 min of training and retraining are superimposed.

stantial impairment of learning relative to the training performance of the experimental group; the impairment was more severe in the second $15 \mathrm{~min}$ of testing $[\mathrm{t}(23)=4.2, \mathrm{p}<.01]$ than in the first $[t(23)=3.1, p<.01]$.

Part B. Performance was better when the longer shock was used; the animals had a higher diptime throughout training, and therefore received fewer shocks. The mean diptime over the 15-min training period was $48.8 \mathrm{sec} / \mathrm{min}$ in Part B and $39.7 \mathrm{sec} / \mathrm{min}$ in Part A $[\mathrm{t}(54)=2.6, p<.01]$. The difference in diptime between trained animals and yoked controls-30.1 sec/min-was also significantly greater than that observed in Part $A[t(54)=2.1$, $\mathrm{p}<.05]$. There was a significant difference in the activity of trained animals in the two experiments6.1 dips/min in Part A and $9.3 \mathrm{dips} / \mathrm{min}$ in Part B $[\mathrm{t}(54)=1.7, \mathrm{p}<.05]$.

Part C. Retraining performance was slightly worse, overall, than training performance, but the difference was not significant. The mean $( \pm S E M)$ difference in diptime between training and retraining was $-1.1( \pm 21.6)$ for the first $6 \mathrm{~min}[\mathrm{t}(23)=.05$, $p>.1]$ and $35.9( \pm 33.7)$ for the whole $15 \mathrm{~min}$ $[\mathrm{t}(23)=1.07, \mathrm{p}>.1]$. Performance during training and retraining is shown in Figure 5 . At no point did the curves differ significantly ( $p>.1, t$ tests). Results for the number of dips made during training and retraining were similar to those above. Training and retraining scores did not differ significantly at any time $(p>.1, t$ tests). There was, therefore, no evidence of retention of the leg-lowering response. 


\section{Discussion}

The results of Parts A and B confirm Pritchatt's observations that the preparation is capable of learning either a lifting or a lowering response to avoid shock (Pritchatt, 1968, 1970). This goes some way to meeting the question of whether the preparation really learns (Church \& Lerner, 1976), since it apparently chooses the appropriate adaptive response (up or down). However, the greater efficacy of 2.0-msec shocks as compared with $0.2-\mathrm{msec}$ shocks, is cause for caution: $0.2-\mathrm{msec}$ shocks produced reflex leg movements, which usually raised the leg, by flexion at the trochanteral-femural joint. Flexion at the trochanter was also produced by the longer shock, but superimposed on this was flexion at the femural-tibial joint, causing a downward twitch, of much greater amplitude; in addition, a continuous train of $2.0-\mathrm{msec}$ shocks produced a steady downward displacement of the leg. (These effects were reflected in the higher rate of dipping observed in Part B.) It is clear from these observations that the unconditioned responses to shock form an important behavioral substrate for the "learned" response, and some form of "reactive" model may yet serve to explain these findings.

The results of Part $\mathrm{C}$ confirm the finding of Experiment 1; in the absence of artifact, there was no evidence of savings on relearning. The conclusion that the preparation does not remember is examined further in the following experiment.

\section{EXPERIMENT 3}

The availability of two responses-lifting and lowering-affords the opportunity to investigate transfer between the two tasks. If, as hypothesized, the preparation does not retain information, then the learning of one task should not interfere with the subsequent learning of a second. The present experiment investigated transfer in both directions: from lifting to lowering, and vice versa. The effect of varying the time interval between the two tasks was also studied.

\section{Method}

Four groups of 25 cockroaches were used in Part A, and two groups of 40 in Part B. The animals were prepared as for Experiment 1. The position at which the leg just made contact with the saline was measured during a 6-min period prior to training; the heights recorded did not differ significantly from those observed in Experiment 1.

In Part A, all animals then received 10 shocks $(.4 \mathrm{~mA}, .2 \mathrm{msec}$, $1 / \mathrm{sec}$ ), and training began $20 \mathrm{sec}$ later. There were two 15 -min training periods (Phases 1 and 3), separated by 15 min (Phase 2). The four groups were treated as follows: Group 1 was first trained to lift (shock contingent on dip) and then trained to dip (shock contingent on lift). Group 2 was yoked to Group 1 in Phase 1 and was trained to dip in Phase 3. Group 3 was trained to dip and was then trained to lift. Group 4 was yoked to Group 3 in Phase 1 and was trained to lift in Phase 3.

Whenever the animals were being trained to dip, a $2.0-\mathrm{msec}$ shock was used, and whenever they were being trained to lift, a .2-msec shock was used. Thus, Groups 1 and 2 received .2-msec shocks in Phase 1 and 2.0-msec shocks in Phase 3, while the reverse was true for Groups 3 and 4.

The procedure described for Group 3 was applied to all animals in Part B. The interval between training to dip and training to lift was $15 \mathrm{~min}$ for one group and 0 for the second.

\section{Results}

Part A. During training on the lifting task (Figure 6a), there was no difference in the diptime of naive experimental animals and reversed experimentals $[\mathrm{t}(24)=1.1, \mathrm{p}>.05]$; both showed a highly significant decrease in diptime relative to (naive) yoked controls $[\mathrm{t}(24)=6.1,6.8 ; \mathrm{p}<.001]$. Experimental animals which had previously been yoked were greatly impaired in their performance relative to naive and reversed groups $[\mathrm{t}(24)=3.1$, $2.9 ; p<.01]$, and did not, in fact, differ significantly from (naive) yoked controls $[\mathrm{t}(24)=1.8$, $p>.05]$.

The picture for the lowering task (Figure 6b) is a mirror image of that just described. Naive experimentals and reversed experimentals did not differ significantly $[\mathrm{t}(24)=1.75, \mathrm{p}>.05]$; both showed a highly significant increase in diptime relative to naive yoked controls $[\mathrm{t}(24)=4.8,5.8 ; \mathrm{p}<.001]$. Experimental animals which had previously been yoked were impaired relative to naive experimentals $[\mathrm{t}(24)=2.85, \mathrm{p}<.01]$ and reversed experimentals $[t(24)=4.7, p<.001]$, and did not differ significantly from (naive) yoked controls $[\mathrm{t}(24)=1.2$, p > .05].

Part B. Immediate reversal training produced a significant impairment of learning. The group a. LIFTIMG

-- I-Naive experimental

$\Delta-\Delta$ 2-Yoked to I

-.-3-Ex-trained to lower

$0-0$-Ex-yoked to 3

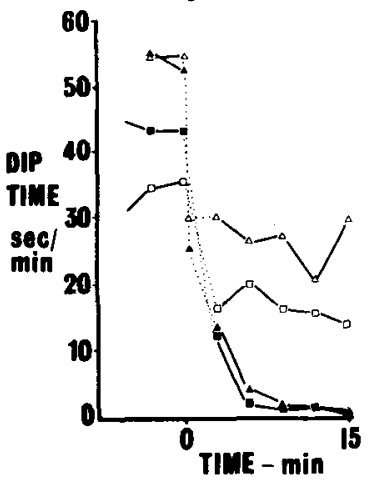

b. LOWERING

-.- 1-Ex-trained to lift

$\Delta-\Delta$ 2-Ex-yolked to I

-- 3-Naive experimental

4-Yoked to 3

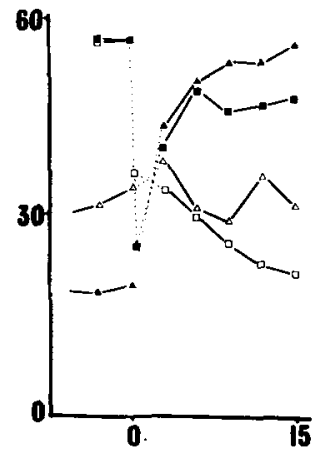

Figure 6. Reversal learning. Groups of animals were trained to lift the leg $15 \mathrm{~min}$ after being trained to lower the leg, and vice versa. Animals which were yoked controls in the first training period were also trained in the second period. (a) Performance of all groups on the lifting task (Phase 1 for Groups 1 and 2, Phase 3 for Groups 3 and 4). (b) Performance of all groups on the lowering task (Phase 1 for Groups 3 and 4 , Phase 3 for Groups 1 and 2). 
trained to lift $15 \mathrm{~min}$ after being trained to lower received a mean of 67.8 shocks, while the group reversed immediately received a mean of 127.7 shocks $[\mathrm{t}(24)=2.9, \mathrm{p}<.01]$.

\section{Discussion}

There was no evidence in this experiment that reversal learning was impaired relative to initial learning, following a 15-min delay. This result does not appear to hold in the case of intact cockroaches. Pritchatt (1970), using a similar postural learning task found that intact animals originally trained to dip showed no evidence of learning to lift when reversed, and although animals originally trained to lift did show reversal learning, this was not statistically significant at the first reversal. Longo (1964) trained cockroaches in a Y-maze; in the one experiment for which the data are presented for original learning and for reversal, there was a considerable impairment on the first day of reversal training. There have been few studies of reversal learning in other invertebrates. Thompson (1957) found no improvement over successive reversals in the sowbug Armadillidum vulgare, but no impairment either. However, data were presented as days or errors to criterion; this might have masked an impairment on the first day of reversal training, for which data were not reported. Impairments on reversals were found by Datta (1962) in the earthworm, by Datta et al. (1960) in the crab, and by Mackintosh and Mackintosh (1964) in the octopus. Unimpaired reversal learning is not therefore a general feature of invertebrate behavior.

There are a number of situations in which reversal might be as good as or better than original learning. For example, if one of a pair of responses were preferred to the other, then reversal from the nonpreferred to the preferred response might be facilitated. This may be ruled out as an explanation in the present experiment, since reversal was unimpaired in either direction. A second example is the overtraining reversal effect (Paul, 1965; Reid, 1953); in animals solving discrimination problems, the ease of reversal is often related to the number of trials given beyond criterion-the more overtraining, the easier the reversal. However, explanations of this kind would not be able to account for the fact that an impairment of learning was found with immediate reversal. The simplest explanation of these results would be that the preparation did remember the previously correct response for a short time, which interfered with immediate reversal learning, but did not remember after $15 \mathrm{~min}$.

\section{GENERAL DISCUSSION}

Experiment $3 \mathrm{~b}$ showed that the learning of a lifting response was impaired immediately following the learning of a lowering response. However, Experiment 3a showed that there was no impairment of reversal learning $15 \mathrm{~min}$ after the original training; Experiment 2 showed that no savings were seen on retraining in the lowering task; and Experiment 1 showed that savings were found on retraining in the lifting task but that this was an artifact of differences in the position of the leg at the start of retraining. Taken together, these results lead to the conclusion that the headless cockroach does not remember the correct response for as long as $15 \mathrm{~min}$. This conclusion must severly undermine the usefulness of the preparation for the study of the physiological bases of memory.

Surprisingly, there is no serious discrepancy between this conclusion and results in the literature. Apart from a few isolated observations for which experimental details are not available (see Eisenstein, 1972), only three previous studies have investigated the problem in the headless preparation. Aranda and Luco (1969) found savings on retraining isolated metathoracic ganglion preparations for up to $30 \mathrm{~min}$ after training, but not at 1 or $24 \mathrm{~h}$. The results agree very closely with those of Experiment 1, and since the authors did not report any attempt to control the position of the leg during retraining, the same artifact may be presumed to apply. Eisenstein (1970b) reported a biphasic memory curve, similar to the Kamin effect (Kamin, 1957), with memory worst $1 \mathrm{~h}$ after training, and an improvement thereafter. These results are difficult to interpret, since the only datum reported was the difference in performance between trained animals and yoked controls, from which it is not possible to deduce whether or not the trained group showed savings on retraining. Scrutiny of the results (Eisenstein, 1970b, Figure 1) suggests that probably this was the case 10 min after training, but not thereafter. Eisenstein and Cohen (1965) did find savings on retraining after $15 \mathrm{~min}$, in isolated prothoracic ganglion preparations, but also found very similar results in isolated prothoracic preparations from which the prothoracic ganglion had been removed.

It is important to distinguish two ways in which the word memory is used. The word may refer to a change in presently observed behavior, or to a predisposition to behave in a different way in response to the same stimulus. The former usage is more common in the physical sciences-for example, hysteresis in metals or in RNA molecules (Katchalsky \& Oplotka, 1966) is spoken of as a memory phenomenon - while the latter is more usual in psychology. It is suggested that the memory shown by animals trained to lift is an artifact of a "physical memory," i.e., a change in the position of the leg, rather than an association between leg position and shock, which would predispose it to 
avoid shock more rapidly on retraining. Any means of persuading the animal to hold its leg at a particular height (e.g., electrical stimulation of the CNS) should produce the same retraining scores. The time elapsed since training and even the fact that the change was produced by training, rather than by some other method, are irrelevant.

This hypothesis receives support from the finding of Rick et al. (1972) that orotic acid increased the time required to reach a criterion of extinction, without affecting acquisition or relearning time: $1 \mathrm{mg}$ orotic acid increased extinction time from a control value of $12 \mathrm{~min}$ to $137 \mathrm{~min}$. The important point is that relearning time was unaffected. This result is readily understandable in terms of the present hypothesis, according to which the relearning score depends only on the position of the leg during extinction rather than on the time elapsed since training.

Horridge (1965) found that following training, stimulation of the ventral nerve cord with shocks in the range of $1-10 / \mathrm{sec}$ abolished all trace of the original learning and animals then showed no savings in relearning. It has been suggested (Miller, 1971) that this may be similar to the effects of electroconvulsive shock in vertebrates, which in some circumstances causes amnesia for preceding events. The present hypothesis suggests an alternative explanation. Touching the abdomen of a cockroach causes transient downward leg movements; stimulation of the abdominal nerve cord could also cause such movements, and prolonged stimulation could produce a long-term change in leg position. Such stimulation would thus cause extinction of the response, with a consequent failure to show savings in retraining.

While the headless preparation is apparently unable to retain information for more than a few minutes, this does not seem to be the case in intact insects. Chen et al. (1970) showed that learning and retention of a classically conditioned response were far better in intact insects than in headless insects, and intact insects retained the response for up to 8 days. Retention of a darkavoidance task has been demonstrated for up to 48 h (Minami \& Dallenbach, 1946) and retention of a maze has been shown for several weeks (Eldering, 1919). In a continuous dark-avoidance task, which formally resembles the tasks used in the present experiments, no decline in performance was seen over $2 \mathrm{~h}$ following a 15 min training period (Lovell \& Eisenstein, 1972). Disterhoft et al. (1968) have reported differences in intact cockroaches between previously trained and previously yoked animals, on retraining in the leg-lifting task after $24 \mathrm{~h}$ (although it is not clear whether trained animals showed savings on retraining at this time).
The behavior of yoked control subjects is difficult to explain. Yoked controls were impaired in learning both lifting and lowering responses. The impairment of lifting persisted for up to $1 \mathrm{~h}$ after training. The gradual decline in the impairment cannot be accounted for by the leg position artifact described above, since if anything, the gradual change in the position of the leg would lead to an increase in the size of the impairment with time. Eisenstein and Cohen (1965) hypothesized that the yoked control undergoes a learning experience essentially similar to that of the trained animal, but while the trained animal learns a single association between shock and leg position, the yoked control learns many such associations, since shock may be received when the leg is in any position. It was postulated that these multiple associations subsequently interfere with learning, when the opportunity to avoid shock is made available. However, if, as argued in the present paper, the preparation does not retain a single association, it would be unlikely to retain multiple associations. It seems, therefore, that a single principle cannot underlie the changes in behavior shown by trained animals and yoked controls. The yoked control impairment is more likely to prove to be a form of habituation, although it is unclear why this should not also be shown by trained animals. The persistence of the impairment does, however, appear to be a genuine memory phenomenon, which might repay further study. (Paradoxically, this might involve using previously trained animals as controls.)

Does the headless cockroach learn? The fact that the preparation can "learn" one of two alternative adaptive responses suggests that the answer to this question is "yes." However, taking into account the apparent lack of memory, the unexplained behavior of the yoked controls, and the strictures of Church and Lerner (1976), it might be safer to continue to retain an open mind on the subject.

\section{REFERENCES}

Aranda, L. C., \& Luco, J. V. Further studies on an electrical correlate to learning. Experiments on an isolated insect ganglion. Physiology \& Behavior, 1969, 4, 133-137.

BOLles, R. C. Species-specific defense reactions. In F. R. Brush, (Ed.), Aversive conditioning and learning. New York: Academic Press, 1971.

Chen, W. Y. Aranda, L. C., \& Luco, J. V. Learning and longand short-term memory in cockroaches. Animal Behaviour, 1970, 18. 725-732.

Church, R. M. Systematic effect of random error in the yoked control design. Psychological Bulletin, 1964, 62, 122-131.

Church, R. M., \& Lerner, N. D. Does the headless roach learn to avoid? Physiological Psychology, 1976, 4, 439-442.

COHEN, M. E. A comparison of invertebrate and vertebrate central neurons. In F. O. Schmitt. (Ed.), The neurosciences: A second study programme. New York: Rockefeller University Press. 1970. 
DatTA, L. G. Learning in the earthworm, Lumbricus terrestris. American Journal of Psychology, 1962, 75, 531-553.

Datta, L. G., Milstein, S., \& BitTerman, M. E. Habit reversal in the crab. Joumal of Comparative and Physiological Psychology, 1960, 53, 275-278.

DisterhofT, J. F. Learning in the intact cockroach (Periplaneta americana) when placed in a punishment situation. Journal of Comparative and Physiological Psychology, 1972, 79, 1-7.

Disterhoft, J., Nurnberger, J., \& Corning, W. C. 'P-R' differ ences in intact cockroaches as a function of testing interval. Psychonomic Science, 1968, 12, 205-206.

Eisenstein, E. M. The effects of CNS lesions on the demonstration of shock avoidance learning by the roach, $P$. americana. Physiologist, 1967, 10, 160.

EIsenstein, E. M. A comparison of activity and position measures of avoidance learning in the cockroach, $P$. americana. Brain Research, 1970, 21, 143-147. (a)

Eisenstein, E. M. The retention of shock avoidance learning in the cockroach, $P$. americana. Brain Research, 1970 , 21, 148-150. (b)

EISENSTEIN, E. M. Learning and memory in isolated insect ganglia. Advances in Insect Physiology, 1972, 9, 111-181.

Eisenstein, E. M., \& Cohen, M. J. Learning in an isolated prothoracic ganglion. Animal Behaviour, 1965, 13, 104-108.

Eldering, F.J. Acquisition d'habitudes par les insectes. Archives Néerlandaises de physiologie, 1919, 3, 469-490.

HorridGe, G. A. Learning of leg position by the nerve cord of headless insects. Proceedings of the Royal Society of London (Series B), 1962, 157, 33-52.

Horridge, G. A. The electrophysiological approach to learning in an isolatable ganglia. Animal Behaviour, (Supplement 1), $1965,163-182$.

Hoyle, G. Neurophysiological studies on 'learning' in headless insects. In J. E. Treherne, \& J. W. L. Beaument (Eds.), The physiology of the insect central nervous system, London: Academic Press, 1965.

KAMIN, L. J. The retention of an incompletely learned avoidance response. Journal of Comparative and Physiological Psychology, $1957,50,457-460$.

KANDEL, E. R. An invertebrate system for the cellular analysis of simple behaviours and their modification. In F. O. Schmitt, \& F. G. Worden (Eds.), The neurosciences: Third study programme. Cambridge, Mass: MIT Press, 1974.

KANDEl, E. R., \& SPENCER, W. A. Cellular neurophysiological approaches in the study of learning. Physiological Reviews, $1968,48,65-134$.

Katchalsky, A., \& Oplotka, A. Hysteresis and macromolecular memory. Israel Joumal of Medical Science, 1966, 2, 4-13.

Kerkut, G. A., Olivek, G. W. O., Rick, J. T., \& WAlker, R. J.
The effects of drugs on learning in a simple preparation. Comparative and General Pharmacology, 1970, 1, 437-483.

Longo, N. Probability-learning and habit-reversal in the cockroach. American Journal of Psychology, 1964, 77, 29-34.

Lovell, K. L., \& EisensteIN, E. M. Dark avoidance learning and memory disruption by carbon dioxide in cockroaches. Physiology \& Behavior, 1972, 10, 835-840.

Maçkintosh, N. J., \& Mackintosh, J. Performance of octopus over a series of reversals of a simultaneous discrimination. Animal Behaviour, 1964, 12, 321-324.

MrleER, P. L. Studies of learning in the insect central nervous system. In G. Horn \& R. Hinde (Eds.), Short term changes in neural activity and behaviour. London: Cambridge University Press, 1971.

Minami, H., \& Daleenbach, K. M. The effect of activity upon learning and retention in the cockroach, Periplaneta americana. American Journal of Psychology, 1946, 59, 1-58.

PavL, C. Habit reversal in rats. Psychological Bulletin, 1965, 63, 65-72.

Pritchatt, D. Avoidance of electric shock by the cockroach, P. americana. Animal Behaviour, 1968, 16, 178-185.

PRItchatT, D. Further studies on the avoidance behaviour of Periplaneta americana to electric shock. Animal Behaviour, $1970,18,485-492$.

RELD, L. S. The development of non-continuity behaviour through continuity learning. Journal of Experimental Psychology, 1953, 46, 107-112.

Rick, J. T., Oliver, G. W. O., \& Kerkut, G. A. Acquisition, extinction and reacquisition of a conditioned response in the cockroach: The effects of orotic acid. Quarterly Journal of Experimental Psychology, 1972, 24, 282-286.

Seligman, M. E. P., \& Hager, J. L. (Eds.). Biological boundaries of learning, New York: Appleton-Century-Crofts, 1972.

SprotT, D. A. Note on Evans and Anastasio on the analysis of covariance. Psychological Bulletin, 1970, 73, 303-306.

Thompson, R. Successive reversals of a position habit in an invertebrate. Science, 1957, 126, 163-164.

Vowles, D. M. Neural mechanisms in insect behaviour. In W. H. Thorpe \& O. L. Zangwill (Eds.), Current problems in animal behaviour, London: Cambridge University Press, 1966.

Willner, P. Learning in a simple system. D. Phil. thesis, University of Oxford, 1974.

Willner, P., \& Mellanby, J. Cholinesterase activity in the cockroach CNS does not change with training. Brain Research, $1974,66,481-490$.

(Received for publication November 29, 1976; revision accepted March $10,1978$. 